\title{
Renal Transplantation in Children
}

\section{Analysis of 25 Consecutive Transplants in 19 Recipients}

\author{
B. HULME, J. R. KENYON, K. OWEN, M. SNELL, J. F. MOWBRAY, K. A. PORTER, \\ S. J. STARKIE, * H. MURAS, † and W. S. PEART \\ From St. Mary's Hospital, and the Department of Experimental Pathology, St. Mary's Hospital Medical School, \\ London
}

\begin{abstract}
Hulme, B., Kenyon, J. R., Owen, K., Snell, M., Mowbray, J. F., Porter, K. A., Starkie, S. J., Muras, H., and Peart, W. S. (1972). Archives of Disease in Childhood, 47, 486. Renal transplantation in children: analysis of 25 consecutive transplants in 19 recipients. Eighteen children aged 6 to 17 years received 24 cadaveric renal transplants between January 1965 and July 1971, and a further child received a kidney donated by her father. 12 children are alive with good functioning grafts and another 2 children are alive on haemodialysis awaiting a further renal graft. The clinical problems of renal transplantation in children are discussed with particular reference to the side effects of immunosuppressive therapy.
\end{abstract}

The eighth report of the Human Kidney Transplant Registry (Murray, Barnes, and Atkinson, 1971) shows that over 4800 renal homotransplants have been performed. The 1-year survival rates for living related ( $87 \%$ ) and cadaver $(52 \%)$ donor transplants have justified the use of this procedure as one method for treatment of irreversible renal failure. Regular haemodialysis is an alternative procedure which has been practised for over 10 years and the technique is well established (Scribner, 1967). The role, if any, of these forms of treatment for children with end-stage renal disease is uncertain (Riley, 1964; Reinhart, 1970), though there have been a number of papers reporting the results of either haemodialysis (Fine et al., 1969) or transplantation (Starzl et al., 1966; Williams, Lee, and Hume, 1969; Fine et al., 1971) in the U.S.A. A recent report (Jones et al., 1971) on haemodialysis and transplantation in the United Kingdom and Eire showed there were 74 patients under the age of 16 years receiving regular haemodialysis in 17 centres. In addition, 45 children had received renal transplants, 16 of which were from a living related donor. We wish to report our experience with 19 children under the age of 18

\footnotetext{
Received 2 February 1972.

^Present address: National Tissue Typing Reference Laboratory, South West Regional Transfusion Centre, Bristol.

tPresent address: Department of Sociology and Social Administration, University of Southampton.
}

years, who received renal transplants between January 1965 and July 1971.

\section{Materials and Methods}

Patients. The children were accepted into the programme on the understanding that they would receive a renal transplant, and no patient was selected for permanent haemodialysis therapy. The length of time spent on supportive treatment was dictated by the availability of a suitable cadaveric organ. The age, sex, primary renal disease, and the time interval on peritoneal or haemodialysis before transplantation of the patients are shown in Table I. Each individual is identified by a unit number allocated at the time of transplantation and the same sequence has been used in a previous publication (Pletka et al., 1969).

Preoperative management. 8 of the 19 children received peritoneal dialysis for a mean time of 3.8 months (range 1.5 to 6 months) before transplantation and the technique used in this centre has been reported previously (Cohen and Percival, 1968). 9 children were maintained by regular haemodialysis treatment for two to eighteen months; 8 were dialysed with disposable $\mathrm{G}$ coil dialysers, and Case 143 with an adult size Kiil dialyser. One child, Case 118, received a renal transplant without a period of supportive therapy.

Before acceptance into the programme particular emphasis was placed on urological investigations of the lower urinary tract to exclude an obstructive uropathy as a cause of chronic renal failure. A bilateral nephrec- 
TABLE I

Clinical Details of Renal Transplant Recipients

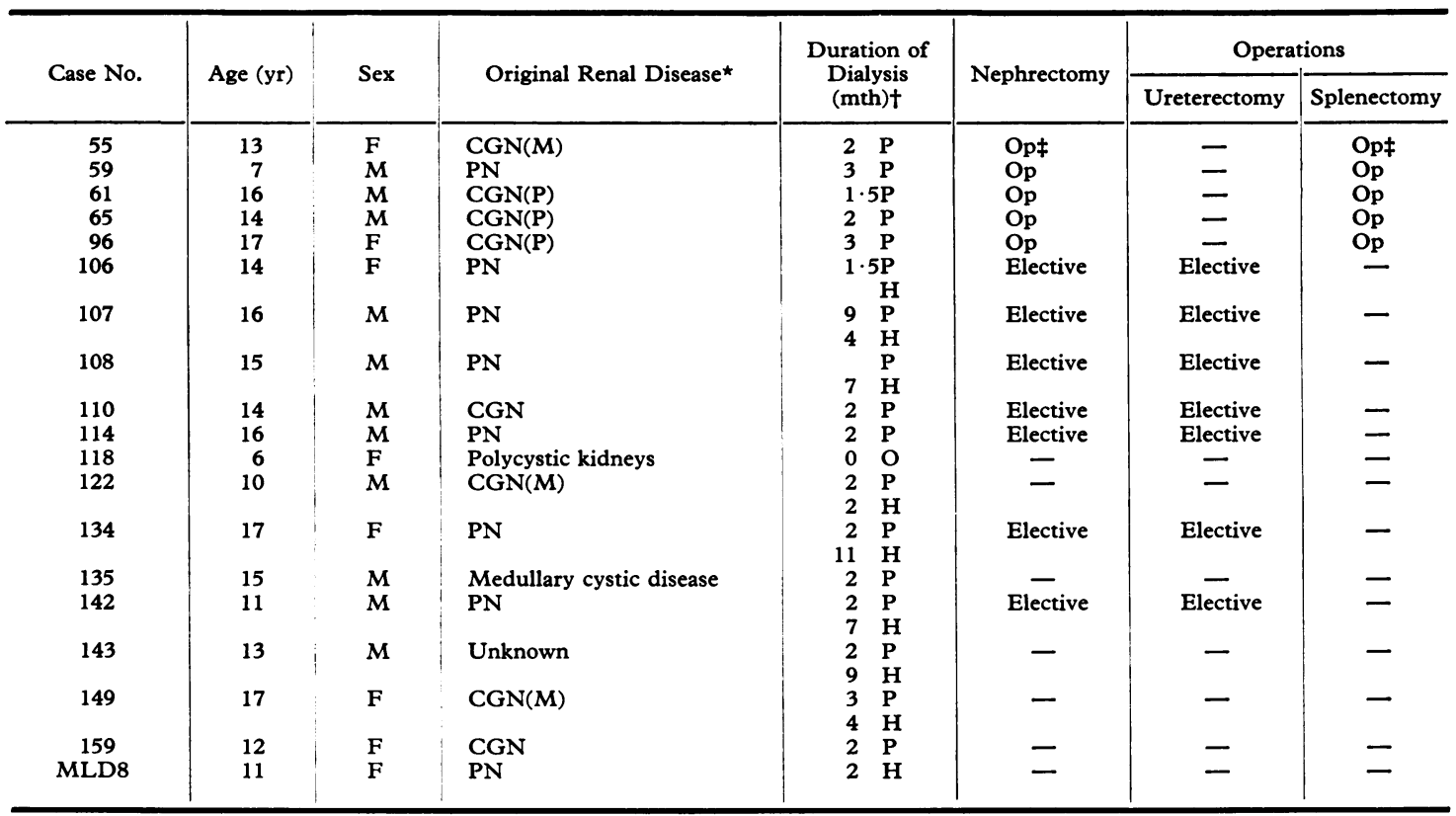

$\star \mathrm{CGN}(\mathrm{M})=$ Chronic membranous glomerulonephritis; $\mathrm{CGN}(\mathrm{P})=$ chronic proliferative glomerulonephritis; $\mathbf{P N}=$ pyelonephritis; $\mathrm{CGN}=$ chronic glomerulonephritis.

$\ddagger$ Op $=$ organs removed at time of transplant operation. tPeritoneal $(\mathrm{P})$ or haemodialysis $(\mathrm{H})$.

tomy and splenectomy were undertaken at the time of the transplant procedure in the 5 children treated before March 1968. An elective bilateral nephrectomy and removal of ureters were performed on 7 children, 6 of whom had pyelonephritis and reflux; the kidneys were not removed in the remaining 7 children.

Histocompatibility testing. All patients received kidneys from ABO blood group compatible donors. Lymphocyte histocompatibility testing was undertaken on 15 donor-recipient pairs using a micromodification of Van Rood's leucoagglutination test (Van Rood and Van Leeuwen, 1963). No child had evidence of preformed cytotoxic antibodies directed against the donor lymphocytes (Patel and Terasaki, 1969), though Case 143 developed antibodies directed against $90 \%$ of a random panel of donors.

Surgical technique. The date of the transplant procedure, donor age, and organ ischaemia times are shown in Table II; the organ ischaemia warm time was defined as the period from death to the kidney being placed in ice-cold saline and the time required to perform the vascular anastomosis. The organs were removed by a technique reported previously (Ackermann and Snell, 1968) and they were not perfused. The kidneys were placed retroperitoneally in the iliac fossa as described by Küss, Teinturier, and Milliez (1951); a bladder catheter remained in place for the first 3 to 7 days and a ureteric catheter was removed after 2 days.

Immunosuppression. The children were given 5 $\mathrm{mg} / \mathrm{kg}$ azathioprine at the time of transplantation and the subsequent dosage was dependent on renal function (Mowbray et al., 1965). If the creatinine clearance were greater than $20 \mathrm{ml} / \mathrm{min}, 3 \mathrm{mg} / \mathrm{kg}$ daily were given and this was reduced to $1 \cdot 0-1.5 \mathrm{mg} / \mathrm{kg}$ in the presence of lower creatinine clearances. During the first 24 hours after transplantation each child was given $200 \mathrm{mg}$ hydrocortisone every 6 hours, and subsequently immunosuppression was maintained with prednisone $20 \mathrm{mg}$ daily, irrespective of body weight, until the onset of the first rejection episode. At this time the prednisone dosage was increased to $200 \mathrm{mg}$ daily and reduced stepwise every 5 days until a maintenance dosage of 15 to $20 \mathrm{mg}$ daily was achieved after 30 to 35 days. The children with creatinine clearances greater than $20 \mathrm{ml} / \mathrm{min}$ at the onset of a rejection episode were given azathioprine $6 \mathrm{mg} / \mathrm{kg}$ for 5 days; in the presence of severe rejection episodes associated with rapid deterioration in renal function, the azathioprine dosage was not increased and often was reduced to $1.0 \mathrm{mg} / \mathrm{kg}$ daily.

Diagnosis of rejection. An acute rejection episode was most easily recognized in the patients with good renal function; under such circumstances a secondary 
TABLE II

Clinical Details of Renal Transplant Donors, Oliguria, and Acute Rejection Episodes

$\star$ Treated electively on the 4 th day.

decline in renal function was considered to be a rejection in the absence of evidence of either ureteric obstruction or vascular occlusions. Other features were the onset of pyrexia, malaise, tachycardia, hypertension, and swelling of the transplant (Mowbray et al., 1965). There was usually a period of oliguria, and laboratory investigations showed a rise in serum creatinine and blood urea concentrations; the urinary sodium and urinary urea concentrations fell and often urinary protein excretion increased. Haematological investigations often showed an eosinophilia and a transient thrombocytopenia.

\section{Results}

Clinical details. 11 of the children in the present series were male and 8 female. The original renal disease was pyelonephritis in 8 cases, chronic glomerulonephritis in 8 , and there were single cases of medullary cystic disease and polycystic renal disease; the renal failure in one instance (Case 143) was of unknown aetiology. The youngest child was aged 6 at the time of transplantation and the majority were 13 years or older. 14 patients received a single transplant and 4 children were given a second renal transplant after failure of the initial graft, while one child (Case 143) has received three transplants.

Histocompatibility testing. An attempt was made to correlate histocompatibility with the num- ber of rejection episodes, the time of the first rejection, and creatinine clearance at $3,6,12,24$, and 36 months after transplantation. In each case the co-ordinates of a linear regression line were calculated, and the probability estimated to test the null hypothesis that, in the whole population, the mean value of the dependent variable does not change with increasing incompatibility (i.e. $\beta=0$ ). It was found that increasing incompatibility did not change the number of rejection episodes, but there was a correlation between the number of antigenic differences and graft function at 36 months $(P=0 \cdot 1)$ though there were only 3 children in this group.

Immediate renal function. Child donor organs were transplanted into 7 recipients while adult kidneys were used in the remaining instances as shown in Table II. There were no problems associated with discrepancies between the size of $N$ the recipient and the renal graft. 10 grafts had an immediate diuresis and postoperative dialysis was unnecessary, while a further 10 transplants suffered acute tubular necrosis and subsequently had a diuresis after a time interval of 4 to 42 days. These children required supportive dialysis, haemodialysis in 6 instances and peritoneal dialysis in the remainder. There was no correlation be- 
tween the duration of 'warm time' and 'cold time' with the presence or absence or tubular necrosis. The period of tubular necrosis in one instance (Case 118) was unknown, as the urine output from her own kidneys was over one litre per day. 4 transplants never functioned; the cause of 2 graft failures in Case 143 was renal vein thrombosis; cortical necrosis was observed in the first transplant of Case 149 and the third transplant of Case 143. This may have been due to either arterial occlusion or acute graft rejection. The first kidney grafted in Case 143 has a 'warm time' of 139 minutes, longer than for any other transplant, and this kidney at the time of graft nephrectomy had a complete renal vein thrombosis. The first kidney grafted in Case 149 had the longest 'cold time' of 389 minutes and this kidney also never functioned. The second transplant in Case 149 had severe tubular necrosis, and though it achieved a creatinine clearance of $18 \mathrm{ml} / \mathrm{min} 23$ days after transplantation it underwent an acute uncontrollable rejection episode and the graft was removed.

\section{Rejection episodes.}

Mild acute. The onset of the first rejection episode was easily recognized in those patients with good renal function associated with minimal tubular necrosis. The day of the first rejection episode varied between 5 and 15 days in these 10 patients, as shown in Table II. 6 patients were treated with increased immunosuppressive therapy from the 4th postoperative day on account of the difficulty in making an early diagnosis of an acute rejection episode in patients with severe oliguria. A further 2 patients (Cases 55 and 122) with evidence of tubular necrosis were maintained on low dosage immunosuppressive therapy throughout the oliguric period, and rejection episodes were diagnosed 6 and 21 days after transplantation. Case 106 received increased immunosuppressive therapy from the first postoperative day of the second transplant procedure, and there has been no evidence of an acute rejection episode.

Severe acute. Severe rejection episodes which were not controlled by increased immunosuppressive therapy were observed in Cases 107 and 118.

Case 107 received a cadaveric renal transplant on 1 September 1968 and there was an immediate diuresis with good renal function for the first 3 days. The graft then suffered an overwhelming rejection, which on histological examination of renal biopsy material was of a cellular type; the rejection process was not reversed with prednisone, actinomycin $\mathrm{C}$, local irradiation to the graft, and the use of horse antilymphocyte serum. After graft nephrectomy there was no evidence of circulating cytotoxic antibodies and he subsequently received a second graft on 28 March 1969 and has had excellent renal function to the present time.

The postoperative management of the second case (Case 118) was somewhat unusual. The child had polycystic kidneys and severe hypertension; renal function tests immediately before transplantation showed a 24-hour urine output of 1 litre with a creatinine clearance of $4 \mathrm{ml} / \mathrm{min}$. Transplantation was undertaken on account of deteriorating renal function and a bilateral nephrectomy was not performed. The renal graft suffered a period of tubular necrosis and 9 days after transplantation the serum creatinine fell and the creatinine clearance rose to $17 \mathrm{ml} / \mathrm{min}$ by 24 days after transplantation. The child had been treated electively for a rejection episode on the 4th postoperative day and a definitive acute rejection was diagnosed on day 28 after transplantation; the creatinine clearance fell to $9 \mathrm{ml} / \mathrm{min}$, and increased immunosuppressive therapy with azathioprine and prednisone did not reverse the process and the graft was removed 41 days after transplantation. After this procedure, renal function slowly declined and the child died 15 months later.

Chronic. The renal transplants of Cases 106 and 108 have undergone a chronic rejection process and both patients underwent graft nephrectomy after 28 months and 4 months, respectively. Both patients received second cadaveric organs, and their clinical progress was as follows.

One patient (Case 106) received his first renal transplant in September 1968 and this graft underwent a slow, relentless rejection process. The original renal disease was well-documented chronic pyelonephritis with marked hydronephrosis and ureteric reflux in a solitary kidney. An elective nephrectomy and ureterectomy was undertaken before transplantation and histological examination of the renal tissue confirmed the diagnosis. After the transplant operation on 1 September 1968 there was an immediate diuresis and mild rejection episodes were diagnosed and treated on the 10th and 20th postoperative days. The rejection process was rapidly reversed and 3 months after transplantation the serum creatinine was only $1.0 \mathrm{mg} / 100$ $\mathrm{ml}$ and the creatinine clearance was $60 \mathrm{ml} / \mathrm{min}$ (Table III). The renal function was excellent until one year after transplantation when the serum creatinine rose to $1.3 \mathrm{mg} / 100 \mathrm{ml}$ and 3 weeks later had risen to 2.5 despite increased immunosuppressive therapy. There was no evidence of ureteric, renal artery, or renal vein obstruction, and the deteriorating renal function was associated with 
Analysis of Renal Function, Organ Failure, a

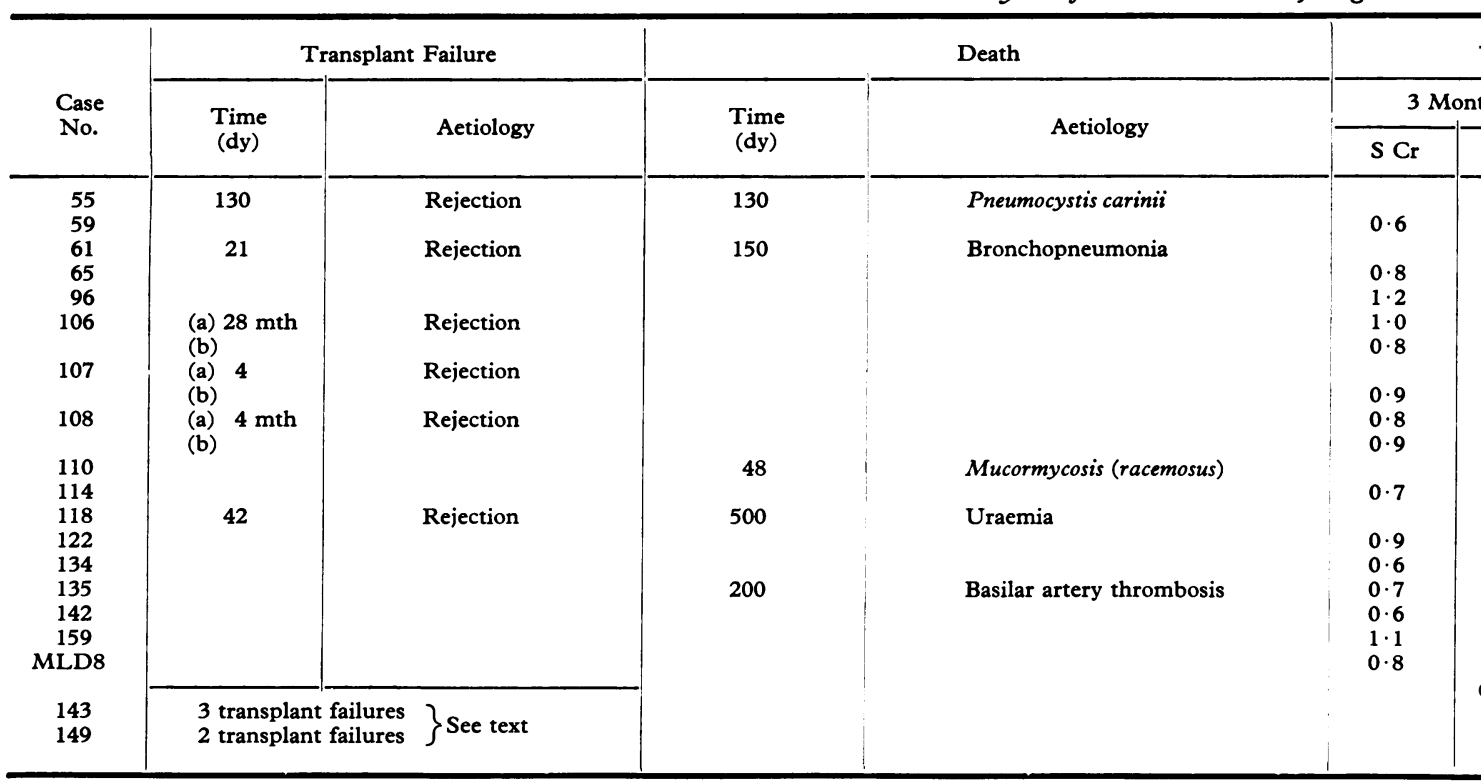

$\star \mathrm{SCr}=$ serum creatinine $\mathrm{mg} / 100 \mathrm{ml} ; \mathrm{Cr} \mathrm{Cl}=$ creatinine clearance $\mathrm{ml} / \mathrm{min}$.

heavy proteinuria of over $5 \mathrm{~g} / 24 \mathrm{hr}$ and severe hypertension. The maintenance dosage of prednisone was increased to $30 \mathrm{mg}$ daily and 2 years after transplantation the serum creatinine had risen to $5 \mathrm{mg} / 100 \mathrm{ml}$ and the creatinine clearance had fallen to $8 \mathrm{ml} / \mathrm{min}$. Renal function continued to deteriorate and it was necessary to undertake intermittent haemodialysis $2 \frac{1}{2}$ years after the transplant procedure. The child received a second graft on 2 July 1971 and at the present time the serum creatinine is $0.8 \mathrm{mg} / 100 \mathrm{ml}$ and creatinine clearance is $60 \mathrm{ml} / \mathrm{min}$.

The first graft of the second patient (Case 108) had excellent renal function for the first 4 months after transplantation and then underwent an irreversible rejection process. After graft nephrectomy, he was maintained on intermittent haemodialysis for 6 months. He had a second transplant on 5 July 1969 and renal function was satisfactory for the first 3 months. However 5 rejection episodes were then treated with increased immunosuppressive therapy and for the past 2 years the patient has had a serum creatinine of 1.6-1.9 $\mathrm{mg} / 100 \mathrm{ml}$ and a creatinine clearance of $20-30$ $\mathrm{ml} / \mathrm{min}$.

\section{Medical Complications Associated with Transplantation}

Infections. Bacterial and fungal infections are a well-recognized complication of renal transplantation and its attendant immunosuppression (Hill et al., 1967). Infection played a dominant role in the deaths of 3 patients in this series. The infections in 2 patients were somewhat unusual but are well documented as complications of impaired immunity.

Case report. Case 110 received a cadaveric renal transplant on 1 October 1968 and, after an initial period of acute tubular necrosis, renal function rapidly improved until the creatinine clearance was $86 \mathrm{ml} / \mathrm{min}$ on the 20th postoperative day. Increased immunosuppressive therapy for a rejection episode was given arbitrarily on the 4th day after transplantation and a definite rejection episode was diagnosed on the 40th postoperative day. The child was given azathioprine $6 \mathrm{mg} / \mathrm{kg}$ and prednisone $200 \mathrm{mg}$ daily for 5 days; the immunosupressive therapy was then reduced in the routine manner but he developed a pyrexia, tachycardia, and shortness of breath. In addition he showed a generalized purpuric rash though his platelet count was $188,000 / \mathrm{mm}^{3}$. Other laboratory investigations showed a total white blood cell count of 5000 cells $/ \mathrm{mm}^{3}$ of which 200 were lymphocytes. The blood urea was $50 \mathrm{mg} / 100 \mathrm{ml}$, serum creatinine $1 \cdot 1 \mathrm{mg} / 100 \mathrm{ml}$, and creatinine clearance $40 \mathrm{ml} / \mathrm{min}$. A chest $x$-ray showed diffuse mottling throughout 


\begin{tabular}{|c|c|c|c|c|c|c|c|c|}
\hline \multicolumn{8}{|c|}{ Renal Function* } & \multirow{3}{*}{ Social Status } \\
\hline \multicolumn{2}{|c|}{6 Months } & \multicolumn{2}{|c|}{12 Months } & \multicolumn{2}{|c|}{24 Months } & \multicolumn{2}{|c|}{36 Months } & \\
\hline $\mathbf{S C r}$ & $\mathrm{Cr} \mathrm{Cl}$ & SCr & $\mathrm{Cr} \mathrm{Cl}$ & $\mathrm{SCr}$ & $\mathrm{Cr} \mathrm{Cl}$ & $\mathbf{S C r}$ & $\mathrm{Cr} \mathrm{Cl}$ & \\
\hline 0.5 & 110 & $0 \cdot 7$ & 70 & $1 \cdot 2$ & 44 & $1 \cdot 2$ & 44 & Stunted: attending normal school \\
\hline $\begin{array}{l}0.9 \\
1.2 \\
0.8 \\
0.8\end{array}$ & $\begin{array}{r}120 \\
65 \\
70 \\
60\end{array}$ & $\begin{array}{l}1 \cdot 2 \\
1 \cdot 1 \\
1 \cdot 3\end{array}$ & $\begin{array}{r}145 \\
90 \\
45\end{array}$ & $\begin{array}{l}1 \cdot 3 \\
1 \cdot 1 \\
4 \cdot 7\end{array}$ & $\begin{array}{r}100 \\
86 \\
8\end{array}$ & $\begin{array}{l}1.6 \\
1.0\end{array}$ & $\begin{array}{r}120 \\
80\end{array}$ & $\begin{array}{l}\text { Working } \\
\text { Working } \\
\text { Working }\end{array}$ \\
\hline $1 \cdot 1$ & 69 & $1 \cdot 0$ & 74 & $1 \cdot 0$ & 65 & & & $\begin{array}{l}\text { Working } \\
\text { At home }\end{array}$ \\
\hline $1 \cdot 7$ & 30 & $1 \cdot 6$ & 23 & $1 \cdot 9$ & 26 & & & \\
\hline $0 \cdot 8$ & 64 & 0.9 & 65 & 0.9 & 68 & & & Complete heart block; working in office \\
\hline $\begin{array}{l}1.0 \\
0.9 \\
0.7 \\
0.7 \\
2.5 \\
0.8\end{array}$ & $\begin{array}{r}65 \\
123 \\
60 \\
75 \\
25 \\
60\end{array}$ & $\begin{array}{l}0.9 \\
1.0\end{array}$ & $\begin{array}{l}70 \\
88\end{array}$ & & & & & $\begin{array}{l}\text { Attending normal school } \\
\text { Working } \\
\text { Attending normal school } \\
\text { Attending normal school } \\
\text { Attending normal school } \\
\text { Home on hospital haemodialysis } \\
\text { Home on hospital haemodialysis }\end{array}$ \\
\hline
\end{tabular}

both lung fields, and serial blood cultures grew Esch. coli. The septicaemia was treated with intramuscular injections of gentamicin without any effect on the pyrexia, dyspnoea, or serial chest radiographs; in addition, arterial oxygen and carbon dioxide tension estimations revealed a normal carbon dioxide tension and a low oxygen tension. A clinical diagnosis of Pneumocystis carinii pneumonitis was made and the patient treated with pentamidine. The chest radiographs showed resolution of the mottling but the dyspnoea became more pronounced. The patient's general condition rapidly deteriorated and he died 10 days after the onset of chemotherapy. Histological examination of lung tissue revealed the presence of Pneumocystis carinii and cytomegalovirus; in addition, the fungus Mucor racemosus was observed within the lung alveoli and was cultured from tissue obtained at necropsy. Both pneumocystis (Rifkind, Faris, and Hill, 1966) and cytomegalovirus (Rifkind, 1965) infections have been well documented in renal graft recipients, but infection with mucor is very unusual.

A further patient (Case 55) died in uraemia due to graft rejection and there were respiratory symptoms for 24 hours before death, similar to Case 1.10

The final child, Case 61, died of bronchopneumonia in 1966 after requiring peritoneal dialysis for 3 months after rejection of the transplant.
Haemodialysis facilities were not available and this death may have been avoidable.

Cardiovascular complications. Two children (Cases 114 and 135) developed complications of the cardiovascular system. Case 135 died of multiple cerebral thrombosis and is reported in greater detail in a later section of this paper.

The second child received a cadaveric renal transplant on 21 December 1968. The original renal disease was pyelonephritis and there had been no evidence of hypertension before transplantation. One year later he had four attacks of loss of consciousness, three of them occurring while he was lying in bed. On examination his heart rate was only $40 / \mathrm{min}$, jugular venous pressure was raised to $4 \mathrm{~cm}$ above the clavicle, and there were occasional cannon waves. An ECG confirmed the diagnosis of complete heart block and there was evidence of an anteroseptal myocardial infarct. An internal pacing catheter was introduced and a permanent internal induction coil pacemaker was inserted on 15 January 1969 . The patient has maintained satisfactory progress with good exercise tolerance and no evidence of cardiac failure or angina.

Corticosteroid complications.

Bone disease. Only one child (Case 55) developed 
clinical evidence of osteoporosis after transplantation. The patient was treated with increased corticosteroid therapy for acute rejection episodes diagnosed on the 4th, 26th, and 44th days after transplantation. 3 months after transplantation the child complained of severe backache localized to the 12th thoracic and 1st lumbar vertebrae. Radiographs showed collapse of several vertebrae in the region. The renal graft had poor function and the child died a short time later.

Weight gain. All the children showed rapid weight gains in the first 2 months after transplantation. However, only one patient (Case 106) showed gross features of hypercorticoidism with marked obesity.

Growth. Corticosteroid therapy is known to cause retardation of growth (Van Metre, Niermann, and Rosen, 1960), and only one child (Case 65) has shown a normal sustained gain in height since transplantation in 1966. In contrast, another child (Case 59) was transplanted in the same year and has received the same steroid therapy but has not grown at all. The other children have shown subnormal growth rates. An attempt was made to transfer from prednisone to ACTH in one child (Case 59) 5 years after transplantation at a time when renal function had been stable for over 3 years. Prednisone was continued and Synacthen $1 \mathrm{mg}$ daily was administered until the plasma cortisol 5 hours after injection was over $50 \mu \mathrm{g} / \mathrm{ml}$. Prednisone was reduced and finally stopped over 14 days while Synacthen was administered daily; 8 days after stopping the prednisone and at a time when the plasma cortisol was greater than 100 $\mu \mathrm{g} / 100 \mathrm{ml}$ renal function rapidly deteriorated, but fortunately the graft responded to large doses of prednisone and renal function returned to the values observed before the alteration in therapy.

Other complications. Nochildren have shown evidence of diabetes mellitus, or avascular necrosis of the femoral heads, but Case 114 has developed cataracts which have been successfully removed.

Transmission of glomerulonephritis. There have been several reports of damage to the renal transplant of a similar type to that observed in the original kidney (Williams et al., 1969; Starzl et al., 1970). The possibility of transmission of the original renal disease to the transplant has been considered in both allografts and transplants between identical twins, but there has been no evidence of this.

Emotional adjustments. There were many practical and emotional problems for the children and their families both before and after transplantation.
Practical and supportive help was offered by a medical social worker to all the patients and their families described in this paper. Many of the problems which were immediately apparent are common to all seriously ill children in hospital. All the families needed clear information and discussion of their child's illness as soon as the child was admitted, and there was always a need to follow this with information about the day-to-day treatment in terms they could understand. If this communication faltered the parents felt unsure of the situation and this was invariably sensed by the patient.

Ten of the 19 patients described lived more than an hour's journey by public transport from the hospital and the majority lived considerably further away, involving their families in complicated, tiring, and expensive journeys to visit the patient. Parents did not complain of the implications of this constant travelling because they were anxious about their sick child, but it often meant that a parent spent a great deal of time hospital visiting and therefore away from the rest of the family. If this situation continued for some months the long-term effect on the family was often great. The sibs would begin to feel neglected and often became jealous of the sick brother or sister. Also it was not only sibs who were affected; at least two families reported that grandparents who were members of the immediate household were jealous of the attention the family were giving the sick child. Reintroducing the patient into the family in these circumstances could become complicated and often needed careful planning.

Patients' families frequently showed signs of prolonged strain. The mother of one boy developed a skin rash which resisted all attempts to relieve it during the time of his illness, while his father suffered two hand injuries at work during the weeks after his son's transfer to this hospital. For the child itself this treatment inevitably meant separation from familiar surroundings usually for the first time, and the need to begin to relate to a group of different adults.

When patients had to follow a strict diet this could in times of particular stress result in the patient regressing to very early attitudes to eating. On one or two occasions it seemed as if the patient had discovered a means of provoking and controlling the staff through neglecting his diet.

As the majority of the patients were aged 13 or older, many of their problems were heightened by the approach of adolescence. They often found difficulty in accepting themselves as unusually small. One boy (Case 135) expressed anxiety about 
being smaller than his younger brothers. He also became very angry at the overprotective attitude this seemed to evoke from his mother while the boys at school often took advantage of him. In contrast to this a boy who was transplanted in 1966 (Case 59) at the age of 7 and has not grown since, seemed remarkably well adjusted 5 years later. This may be largely due to his parents' attitudes but may also be because he has not yet reached adolescence. For children approaching school leaving age, once the illness appeared to be under control, they often worried about the kind of employment they would be able to take up when they left school.

For the staff looking after these children it was necessary to consider the wider implications of the treatment because the children were often in hospital for long periods and inevitably the staff became involved in their lives. Frequent staff discussion of individual patients and their treatment was necessary in order that everyone should gain both perspective and understanding of the situation as it developed. This discussion went some way to help the staff accept parental attitudes and to anticipate changes in the patient's behaviour. This kind of involvement means that the staff becomes part of the child's normal process of growing up and it should be accepted as part of the wider responsibilities of treatment. If this is done, then the child should leave hospital feeling that his experience was something through which he has matured rather than that he should use his illness as an excuse for any future failures.

Mortality. 5 of the 19 children died after the transplantation procedure and the causes of death are listed in Table III. 2 patients died of unusual infections, one due to Mucormycosis and one to Pneumocystis carinii, both well recognized as complications of immunosuppressive therapy.

One child (Case 118) died in uraemia 15 months after rejection of her cadaveric transplant and supportive therapy had not been reintroduced. One child (Case 61) died of bronchopneumonia and has been mentioned earlier. The final child died of a cerebrovascular accident 6 months after transplantation and details are as follows.

The child (Case 135) presented with renal osteodystrophy at the age of 8 . There was no clinical history of renal disease and at no time was he known to be hypertensive. The underlying renal lesion was eventually diagnosed as medullary cystic disease. A successful renal transplant operation was performed on 21 January 1970 . The graft functioned immediately and the only mild rejection episode was diagnosed on the 6 th day after transplantation. He was fully rehabili- tated and maintained satisfactory progress for the first 6 months. However, he was then admitted as an emergency on account of stupor, pronounced occipital headaches, and repeated grand mal epileptiform convulsions of 7 hours' duration. On clinical examination there was no evidence of meningitis, raised intracranial pressure, or localizing neurological signs. Despite anticonvulsant therapy, the patient continued to have grand mal fits and died a short time later. At necropsy, examination of the CNS showed a thrombosis of the basilar, anterior, middle, and posterior cerebral arteries with cortical infarction. There was no evidence of atherosclerosis in the coronary blood vessels.

\section{Discussion}

Riley (1964) has suggested that the success or failure of a renal transplant should not be restricted to gross survival data but should depend on whether the child is leading a normal life without physical or emotional handicaps. Reinhart (1970) also considered that the procedure must be analysed in terms of normal growth and sexual development; indeed Williams et al. (1969) stressed the importance, both for the child and the family, that a fatal disease was not replaced by a chronically debilitating life leading to an eventual fatal outcome. Numerous reports have shown that, technically, transplantation in children is a standard procedure with very few, if any, alterations from the procedure used in adults. However papers have restricted their data to relatively short follow-up periods and many questions remain unanswered. Analysis of the results obtained in this centre reveals that only one child has had a completely successful transplant associated with normal growth and sexual development over a period of $4 \frac{1}{2}$ years. 6 children have left school and are working; all have normal sexual development and are of socially acceptable stature. A further 3 children have normal renal function, and are attending normal schools but have stunted growth as a result of steroid therapy. Attempts have been made, in other centres, to modify steroid therapy by alternateday dosage (Reed, Lucas, and Cohn, 1970) or substitution with parenteral ACTH (Friedman and Strang, 1966) with variable success. At the present time there appears to be no substitute for maintenance steroid therapy, though the use of specific enhancing antibody therapy described by Batchelor et al. (1970) may play a future role. Heterologous antilymphocyte serum or globulin first used clinically by Starzl et al. (1968) has been shown to reduce the amount of steroid therapy required in the early postoperative period. However it has not been possible to maintain immunosuppression with azathioprine alone when cadaveric organs have 
been transplanted (Sheil et al., 1971). It is thought that continuing research into transplantation immunology will either eliminate the need for steroid therapy or will provide a more natural and specific alternative form of immunosuppression. Lymphocyte tissue typing has not been of predictive value in this series of cadaveric renal transplants in children and this topic is still much debated.

The major contributory cause to the mortality associated with renal transplantation is that of infection secondary to the immunosuppressive therapy necessary to prevent rejection of the graft. An analysis of these infections shows that the majority are due to Gram-negative organisms particularly pseudomonas, klebsiella, and Esch. coli. Hill and co-workers (1967) have reported similar results and also discussed the incidence of more unusual infections due to aspergillus, Pneumocystis carinii, and cytomegalovirus. It is generally agreed that the immunosuppressive therapy renders the renal graft recipient more prone to infection and that excessive steroid therapy is particularly important in this respect.

The recurrence of glomerulonephritis in the grafted organ has been reported from a number of centres (Williams et al., 1969; Starzl et al., 1970), and it appears to be a greater risk in children than adults. In this centre none of the 8 children with preceding glomerulonephritis had biopsy evidence of recurrence of the same process after transplantation. One child whose original renal disease was hydronephrosis and pyelonephritis developed heavy proteinuria and impaired renal function one year after transplantation, and this was thought to be due to a chronic rejection process such as reported by Harlan et al. (1967).

We conclude that despite the impaired growth rates of the majority of the children transplanted in this centre the results justify renal transplantation as an acceptable procedure for the treatment of end-stage renal disease.

\section{REFERENCES}

Ackermann, J. R., and Snell, M. E. (1968). Cadaveric renal transplantation: a technique for donor kidney removal. British fournal of Urology, 40, 515 .

Batchelor, J. R., Ellis, F., French, M. E., Bewick, M., Cameron, J. S., and Ogg, C. S. (1970). Immunological enhancement of human kidney graft. Lancet, 11, 1007.

Cohen, S. L., and Percival, A. (1968). Prolonged peritoneal dialysis in patients awaiting renal transplantation. British Medical Fournal, 1, 409.

Fine, R. N., De Palma, J. R., Gordon, A., Maxwell, M. H., Grushkin, C. M., and Lieberman, E. (1969). Haemodialysis in children. Proceedings of the European Dialysis and Transplant Association, $6,149$.

Fine, R. N., Korsch, B. M., Edelbrock, H. H., Riddell, H., Brennan, L. P., Stiles, Q., Grushkin, C. M., and Lieberman, E. (1971). Cadaveric renal transplantation in children. Lancet, 1, 1087.
Friedman, M., and Strang, L. B. (1966). Effect of long-term corticosteroids and corticotrophin on the growth of children. Lancet, 2, 568.

Harlan, W. R., Jr., Holden, K. R., Williams, G. M., and Hume, D. M. (1967). Proteinuria and nephrotic syndrome associated with chronic rejection of kidney transplants. New England Fournal of Medicine, 277, 769.

Hill, R. B., Jr., Dahrling, B. E., II, Starzl, T. E., and Rifkind, D. (1967). Editorial. Death after transplantation: an analysis of sixty cases. American fournal of Medicine, 42, 327.

Jones, J. M. B., Cameron, J. S., Bewick, M., Ogg, C. S., Meadow, S. R., and Ellis, F. G. (1971). Treatment of terminal renal failure in children by home dialysis and transplantation. Archives of Disease in Childhood, 46, 457.

Küss, R., Teinturier, J., and Milliez, P. (1951). Quelques essais de greffe de rein chez l'homme. Mémoires de l'Académie de Chirugie, 77, 755.

Mowbray, J. F., Cohen, S. L., Doak, P. B., Kenyon, J. R., Owen, K. Percival, A., Porter, K. A., and Peart, W. S. (1965). Human cadaveric renal transplantation: report of twenty cases. British Medical Fournal, 2. 1387.

Murray, J. E., Barnes, B.A., and Atkinson, J. C. (1971). Eighth report of the human kidney transplant registry. Transplantation, 11, 328.

Patel, R., and Terasaki, P. I. (1969). Significance of the positive crossmatch test in kidney transplantation. New England fournal of Medicine, 280, 735.

Pletka, P., Cohen, S. L., Hulme, B., Kenyon, J. R., Owen, K., Thompson, A. E., Snell, M., Mowbray, J. F., Porter, K. A., Leigh, D. A., and Peart, W. S. (1969). Cadaveric renal transplantation: an analysis of 65 cases. Lancet, $1,1$.

Reed, W. P., Lucas, Z. J., and Cohn, R. (1970). Alternate-day prednisone therapy after renal transplantation. Lancet, 1, 747.

Reinhart, J. B. (1970). The doctors dilemma: whether or not to recommend continuous renal dialysis or renal homotransplantation for a child with end-stage renal disease. Fournal of Pediatrics, 77, 505.

Rifkind, D. (1965). Cytomegalovirus infection after renal transplantation. Archives of Internal Medicine, 116, 554.

Rifkind, D., Faris, T. D., and Hill, R. B., Jr. (1966). Pneumocystis carinii pneumonia: studies on the diagnosis and treatment. Annals of Internal Medicine, 65, 943.

Riley, C. M. (1964). Thoughts about kidney homotransplantation in children. Fournal of Pediatrics, 65, 797.

Scribner, B. H. (1967). Dialysis. In Renal Disease, 2nd ed., p. 446. Ed. by D. A. L. Black. Blackwell, Oxford.

Sheil, A. G. R., Mears, D., Kelly, G. E., Rogers, J. H., Storev, B. G. Johnson, J. R., May, J., Charlesworth, J., Kalowski, S., and Stewart, J. H. (1971). Controlled clinical trial of antilymphocyte globulin in patients with renal allografts from cadaver donors. Lancet, 1, 359.

Starzl, T. E., Groth, C. G., Terasaki, P. I., Putman, C. W., Brettschneider, L., and Marchioro, T. L. (1968). Heterologous antilymphocyte globulin, histoincompatibility matching, and human renal homotransplantation. Surgery, Gynecology and Obstetrics, 126, 1023.

Starzl, T. E., Marchioro, T. L., Porter, K. A., Faris, T. D., and Carey, T. A. (1966). The role of organ transplantation in pediatrics. Pediatric Clinics of North America, 13, 381.

Starzl, T. E., Porter, K. A., Andres, G., Halgrimson, C. G., Hurwitz, R., Giles, G., Terasaki, P. I., Penn, I., Schroter, G. T., Lilly, J., Starkie, S. J., and Putnam, C. W. (1970). Long-term survival after renal transplantation in humans (with special reference to histocompatibility matching, thymectomy, homograft glomerulonephritis, heterologous ALG, and recipient malignancy). Annals of Surgery, 172, 437.

Van Metre, T. E., Jr., Niermann, W. A., and Rosen, L. J. (1960). A comparison of the growth suppressive effect of cortisone, prednisone, and other adrenal cortical hormones. fournal of Allergy, 31, 531.

Van Rood, J. J., and Van Leeuwen, A. (1963). Leukocyte grouping: a method and its application. Fournal of Clinical Investigation, 42, 1382.

Williams, G. M., Lee, H. M., and Hume, D. M. (1969). Renal transplants in children. Transplantation Proceedings, 1, 262.

Correspondence to Dr. B. Hulme, The Medical Unit, St. Mary's Hospital, London W2. 